The study was supported by a grant from the British Epilepsy Association.

\section{References}

1 Van den Berg, B J, Yerushalmy, J, Pediatric Research, 1976, 3, 298.

2 Nelson, K B, Ellenberg, J H, New England fournal of Medicine, 1976, 295, 1029.

${ }^{3}$ Ounsted, C, Lindsay, J, Norman, R, Clinics in Developmental Medicine, No 22. London, Heinemann, 1966.

+ Millichap, J G, Febrile Convulsions. New York, MacMillan, 1968.
5 Landrigan, P J, and Witte, J J, Fournal of the American Medical Association, 1973, 223, 13, 1459.

${ }^{6}$ Kulenkempff, M, Schwartznan, J S, and Wilson, J, Archives of Disease in Childhood, 1974, 49, 46.

' Melchior, J C, Archives of Disease in Childhood, 1977, 52, 134.

${ }^{8}$ Stewart, G T, Lancet, 1977, 1, 234.

${ }^{9}$ Miller, F J W, et al, Growing up in Newcastle upon Tyne. London, Oxford University Press, 1960.

${ }^{10}$ Lennox-Buchthal, M A, Febrile Convulsions: A Reappraisal. Amsterdam, Elsevier Scientific Publishing Co, 1973.

1 Van den Berg, B J, Developmental Medicine and Child Neurology, 1974, 16, 4, 457.

(Accepted 30 fune 1977)

\title{
Family similarities in the age at coronary death in familial hypercholesterolaemia
}

\author{
ARVID HEIBERG, JOAN SLACK
}

British Medical fournal, 1977, 2, 493-495

\section{Summary}

In a combined Norwegian and British study of the age at death from coronary heart disease of heterozygotes for familial hypercholesterolaemia (FH) the correlation coefficients within families for 43 sib pairs was 0.70 and for 14 first cousin pairs 0.61. There was no significant correlation between the age at death and serum cholesterol concentration in either series.

The intrafamilial correlations suggest that information about the age at death from coronary heart disease in heterozygotes within families may have some prognostic value and may also be interpreted as evidence for genetic heterogeneity in FH.

\section{Introduction}

The risk of early death from coronary heart disease in heterozygotes for familial hypercholesterolaemia $(\mathrm{FH})$ is well documented. ${ }^{1-4}$ There is, however, considerable variation in the age at which the first symptoms of ischaemic heart disease are noted or at which coronary death occurs. The reason for such variation may be associated with differences in serum cholesterol concentration ${ }^{5}$ or other risk factors such as blood pressure and smoking, or it may be associated with heterogeneity of the genetic mutations producing the clinical manifestation of $\mathrm{FH}$.

Many clinicians have observed a specially favourable or poor prognosis for $\mathrm{FH}$ within families but few have had the opportunity to observe enough patients to verify this clinical impression. By combining two studies of families with $\mathrm{FH}$, one from Norway and one from England, where the mortality rates from coronary heart disease in the general population are similar, we were able to investigate similarities within families in

\footnotetext{
Department of Medical Genetics, Institute of Medical Genetics, University of Oslo, Oslo
}

\section{ARVID HEIBERG, DRMED, consultant}

MRC Clinical Genetics Unit, Institute of Child Health, London WC1 JOAN SLACK, DM, MRCP, consultant and honorary senior lecturer the age at death due to coronary heart disease among heterozygotes for $\mathrm{FH}$.

\section{Patients and methods}

The data from two family studies of patients with $\mathrm{FH}-$ one Norwegian with 139 kindreds $^{6}$; and one British ${ }^{8}$ with 33 kindredswere combined. All index patients in the kindreds included in this analysis had tendinous xanthomata and hypercholesterolaemia. The cause of death in all patients contributing to these series was verified as being coronary heart disease from death certificates or hospital records.

Altogether 14 of the Norwegian kindreds and eight of the British kindreds contributed to these analyses of the sib-sib correlation coefficients. In addition 14 first cousin pairs were included from the Norwegian kindreds. The cumulative morbidity and mortality rates for the Norwegian and British series of heterozygotes for FH were remarkably similar."

Serum total cholesterol concentrations were determined by standard methods ${ }^{4}$ and adjusted for age and sex as described.

Statistical analysis-Intrafamilial correlations for age at death due to coronary heart disease were calculated for heterozygous sib pairs and cousins. Only relatives of the same generation were used in these calculations to reduce environmental differences which may have contributed to coronary risks. The significance of $r$ values were tested after $\mathrm{z}$ transformation.9 ${ }^{9}$ The combined probabilities for correlation coefficients in sibs and cousins were obtained as recommended by Sverdrup ${ }^{10}$ with tables for small samples. ${ }^{11}$

\section{Results}

\section{AGE AT DEATH}

The mean ages at death in the sibs of probands with $\mathrm{FH}$ who were used for the intrafamilial correlations are shown in table I. The difference in age at death between the Norwegian and British series was significant for men $(P<0.001)$ but not for women. The age at death for women was converted to the equivalent value for men by subtracting nine years, which was the median difference in age at death in the larger Norwegian and British series of which these families were a subsample. The age at death of sibs of the British index patients with $\mathrm{FH}$ is shown in fig 1. More than one mode of distribution was clearly suggested in the British but not in the Norwegian series. The age at death from coronary heart disease in sib pairs is shown in fig 2. A trend for lower age at death in the British than in the Norwegian sibs was apparent.

An intrafamilial correlation for age at death in sibs was also apparent (fig 2) for each of the series as well as for the combined series. The 
computed results are given in table II. The correlation coefficients were significantly different from zero in the Norwegian and British series separately as well as in the combined series.

A correlation coefficient greater than 0.5 in affected sibs and in first cousins is expected if the condition is caused by a single mutant gene with many modifying genes. Taking the Norwegian and British series separately, neither correlation coefficient was significantly greater than 0.5 but in the combined series the correlation coefficient of 0.70 in sibs was significantly greater than $0.5(P \approx 0.03)$ but that of 0.61 in first cousins was not $(P>0 \cdot 10)$. The correlation coefficients could have been biased by the presence of some large families in the series if a uniform pattern of death had been present. But the two largest threegeneration families gave 11 and six sib pairs with correlation coefficients for age at death in sibs of 0.41 and $-0 \cdot 10$, respectively. The correlation for age at death from other causes in patients without xanthomatosis in the Norwegian series of 139 kindreds was $0 \cdot 15$ in 59 sib pairs and 0.15 in 14 first cousin pairs.

\section{CHOLESTEROL AND AGE AT DEATH}

The intrafamilial correlation for age at death in these series could have been accounted for by variations in cholesterol or low-density lipoprotein concentrations. No significant correlations were found between the adjusted serum cholesterol concentrations and age at death for the British or Norwegian series, either separately $(0 \cdot 12$ and $-0 \cdot 18$, respectively) or combined $(0.03)$. The sib-sib correlation coefficient for cholesterol concentrations was 0.29 for the 29 pairs in these series; this was not significantly different from zero.

\section{Discussion}

The age at which coronary heart disease proves fatal in patients with $\mathrm{FH}$ is likely to depend both on the severity of the effects of the dominant mutant gene and on the environmental and polygenic background against which the effect of the mutant gene is felt. If the genetic defect alone determined the course of the condition then all the heterozygotes for $\mathrm{FH}$ would be expected to die from coronary heart disease at a similar age. But this is clearly not the case. The prognosis is worse in men than in

TABLE I-Mean age at death in different groups of sibs with FH

\begin{tabular}{|c|c|c|c|c|}
\hline & \multicolumn{2}{|c|}{ Men } & \multicolumn{2}{|c|}{ Women } \\
\hline & No & Age & No & Age \\
\hline $\begin{array}{l}\text { Norwegian } \\
\text { British }\end{array}$ & $\begin{array}{l}32 \\
17\end{array}$ & $\begin{array}{l}55 \cdot 1 \pm 10 \cdot 2 \\
40 \cdot 4 \pm 8 \cdot 0\end{array}$ & $\begin{array}{r}25 \\
7\end{array}$ & $\begin{array}{l}64 \cdot 1+11 \cdot 2 \\
58 \cdot 7+10 \cdot 0\end{array}$ \\
\hline
\end{tabular}

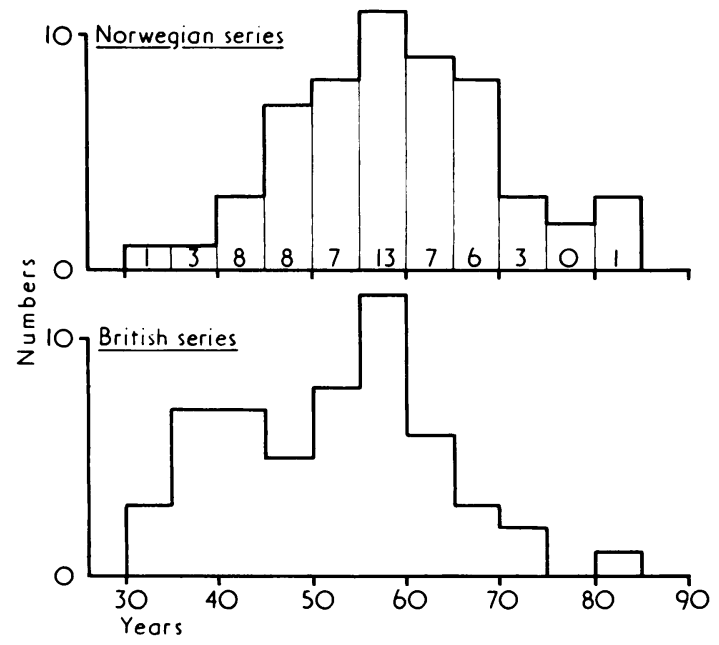

FIG 1-Age at death due to coronary heart disease in affected sibs of index patients with $\mathrm{FH}$ in Norwegian and British series.

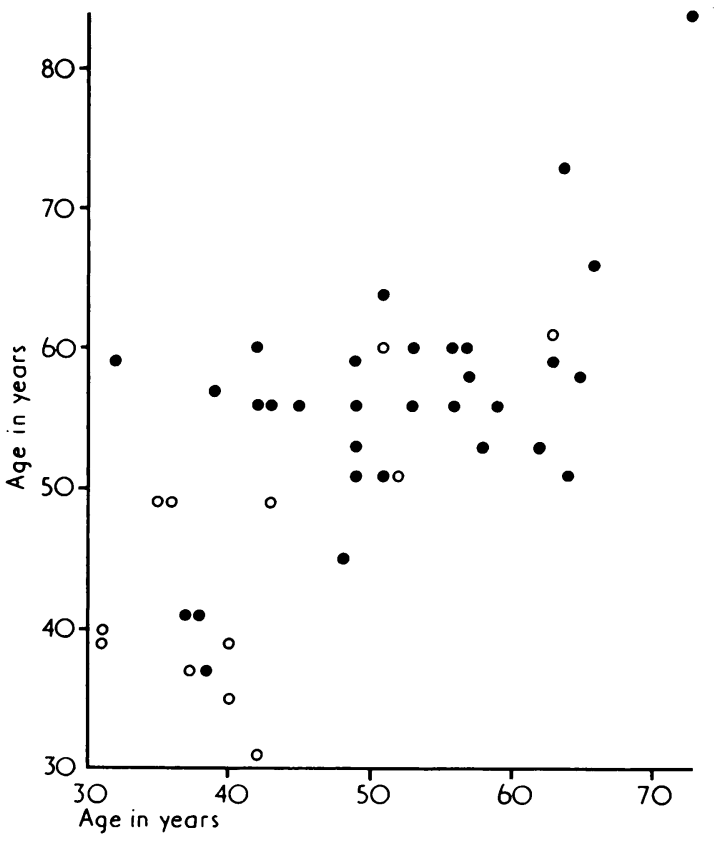

FIG 2-Age at coronary death due to coronary heart disease in affected sib pairs in Norwegian $(\bullet)$ and British $(O)$ series.

TABLE II-Interfamily correlation coefficients for age at death due to coronary heart disease

\begin{tabular}{|c|c|c|c|c|}
\hline \multirow[b]{2}{*}{ Group: } & \multicolumn{3}{|c|}{ Sibs } & \multirow{2}{*}{ First cousins } \\
\hline & Norwegian & British & Combined & \\
\hline $\begin{array}{l}\text { No of pairs } \\
\mathrm{r} \text { values }( \pm S D)\end{array}$ & $\begin{array}{c}31 \\
0.60 \pm 0 \cdot 19 * *\end{array}$ & $0.67 \pm 0.33^{*}$ & $\begin{array}{c}43 \\
0 \cdot 70 \pm 0 \cdot 16^{* *}\end{array}$ & $\begin{array}{c}14 \\
0.61 \pm 0 \cdot 30^{*}\end{array}$ \\
\hline
\end{tabular}

$* P \leqslant 0.05 . \quad * * P \leqslant 0.01$ significance of difference from zero.

women, ${ }^{34}$ and our observations show a range of age at death of 31 to 73 years in men and 41 to 93 years in women. It would be helpful to know some of the factors that contribute to differences in prognosis so that the maintenance of rigid diet and drug treatment could be encouraged in those in whom the outcome of the disease without treatment is likely to be most serious. The clinical impression that there are family similarities in the age at which heterozygotes for $\mathrm{FH}$ die from coronary heart disease is confirmed by our data, both in the combined series and from Norway and England separately.

The combined influence of polygenic inheritance and environmental factors on age at death in heterozygotes for $\mathrm{FH}$ is difficult to evaluate. Most sibs in this series had not lived in the same household for at least 30 years before their death. The similarity of the correlation coefficients in sib pairs with that in cousins probably contradicts a large environmental influence. In general most interacting factors would decrease the correlation in sibs, not increase it. The correlation in age at death from coronary heart disease in patients with xanthomatosis was much higher than that observed for age at death due to other causes in the sibs without xanthomatosis.

No significant correlation was found between the age at death and the cholesterol concentration. This implies that the absolute increase in cholesterol or low density lipoprotein concentrations is of minor importance in the prognosis of heterozygotes for $\mathrm{FH}$.

In 1941 Haldane pointed out that if a disease is determined by a single major gene with many modifying genes affecting the age of onset and, presumably, death and acting independently of each other then the sib-sib correlation will be about $0.5 .{ }^{12}$ If, however, the same clinical syndrome can be produced by several different gene mutations, each having its own narrow age range at onset or death, then the sib-sib correlation will be nearly $1 \cdot 0$. 
Any spread in the age at death due to polygenic or non-familial environmental modification will reduce the correlation.

In 1947 Harris and Smith examined this concept more closely and concluded that, "If for any disease we obtain a parent-child correlation of about 0.5 or more, then we may suspect that there may be two or more genes mimicking one another; such a situation will probably show up by a multimodality in the distribution of ages of onset." 13

Biochemical heterogeneity has been suggested for autosomal dominantly inherited $\mathrm{FH}$ by Brown and Goldstein ${ }^{14}$ and by Higgins et $a l,^{15}$ and biochemical heterogeneity of the gene mutation might also account for some differences in prognosis. We suggest that the observed intrafamilial correlation for the age at death from coronary heart disease in $\mathrm{FH}$ can be accounted for by at least two different gene mutations-each having its own expected age at death but subject to considerable variation by polygenic or environmental modification.

No further evidence for genetic heterogeneity was obtained for serum cholesterol concentrations. Linkage between $\mathrm{FH}$ and the $\mathrm{C} 3$ polymorphism has been reported ${ }^{16}$ - possibly similar to elliptocytosis and the $\mathrm{Rh}$ blood group, where linkage exists for one locus and not for the other. Analysis of the linkage data with respect to this is in progress.

Our findings have clinical implications. The patient's knowledge of his family history affects his attitude towards treatment, and those with families where early death among close relatives is the rule may be more compliant than those with a less tragic family history. As it is possible to diagnose $\mathrm{FH}$ early in life, decisions about treatment can be made early. Half the variation in age at death in sibs heterozygous for the $\mathrm{FH}$ gene(s) is accounted for by the observed correlation.

The biochemical findings of heterogeneity in $\mathrm{FH}$ have received some clinical support from our investigation. Further genetic work must be undertaken to elucidate the importance of genetic heterogeneity in $\mathrm{FH}$, but at least some reassurance may be given to patients with $\mathrm{FH}$ where the family history is known to be good.

This study was supported by grants from the Norwegian Council on Cardiovascular Diseases, J L Tiedemanns Tobaksfabrik, J H Andresens Medisinske Fond, and the Norwegian Research Council for Science and the Humanities.

Requests for reprints should be addressed to $\mathrm{Dr}$ A Heiberg, Institute of Medical Genetics, P O Box 1036, Blindern, Oslo 3, Norway.

\section{References}

${ }^{1}$ Epstein, F H, et al, American fournal of Medicine, 1959, 26, 39.

2 Jensen, J, Blankenhorn, D H, and Kornerup, V, Circulation, 1967, 36, 77.

3 Slack, J, Lancet, 1969, 2, 1380.

- Heiberg, A, Acta Medica Scandinavica, 1975, 198, 249

${ }^{5} \mathrm{Kannel,}$ W B, et al, Annals of Internal Medicine, 1964, 61, 888

${ }^{6}$ Heiberg, A, Clinical Genetics, 1976, 9, 92.

${ }^{7}$ Heiberg, A, and Berg, K, Clinical Genetics, 1976, 9, 203.

8 Nevin, N C, and Slack, J, fournal of Medical Genetics, 1968, 5, 9.

- Snedecor, G W, and Cochran, W G, Statistical Methods, 6 edn. Iowa, Ames, University of Iowa Press, 1967.

10 Sverdrup, E, Laws and Chance Variations. Basic Concepts of Statistical Inference, vol 2, p 144. Amsterdam, North Holland, 1967.

${ }^{11}$ David, F N, Tables of the Ordinates and Probability Integral of the Correlation Coefficient in Small Samples. London, Cambridge University Press, 1938

${ }^{12}$ Haldane, J B S, Fournal of Genetics, 1941, 41, 149.

${ }^{13}$ Harris, H, and Smith, C A B, Annals of Eugenics, 1947, 14, 309.

${ }^{14}$ Brown, M S, and Goldstein, J L, in Progress in Medical Genetics, ed A G Steinberg et al, vol 19, p 103. New York, Grune and Stratton, 1976.

${ }^{15}$ Higgins, M J P, Lecamwasam, D S, and Galton, D J, Lancet, 1975, 2, 737.

${ }^{16}$ Berg, K, and Heiberg, A, in Human Gene Mapping 3, ed D J Bergsma, p 266. Basle, Karger, 1976.

(Accepted 22 June 1977)

\title{
Treatment of acute lymphoblastic leukaemia: effect of variation in length of treatment on duration of remission
}

\author{
Report to the Medical Research Council by the Working Party on Leukaemia in Childhood
}

British Medical fournal, 1977, 2, 495-497

\begin{abstract}
Summary
Patients with acute lymphoblastic leukaemia (ALL) were allocated at random either to stop maintenance chemotherapy after six 12-week courses or continue with a further six. The main difference between the two groups was in the incidence of bone-marrow relapse within nine months after stopping treatment. Such
\end{abstract}

\footnotetext{
Leukaemia Trials Office, Royal Marsden Hospital, London SW3 6JJ REPORT PREPARED BY: Professor R M Hardisty and Dr H E M Kay. MEMBERS OF WORKING PARTY DURING TRIAL: Professor J H Hutchison (chairman); Professor R M Hardisty (secretary); Professor K D Bagshawe; Dr P Barbor; Dr J M Bridges; Professor Neville Butler; Dr J M Chessels; Dr P F Deasy; Sir Richard Doll; Dr P Emerson; Dr H W Everley Jones; Dr D I K Evans; Professor D A G Galton;Dr R J Guyer; Dr C B Howarth; Dr E M Innes; Dr P Morris Jones; Dr H E M Kay (co-ordinator of trial); Dr J Lilleyman; Dr T J McElwain; Dr I C M MacLennan; Dr J Mann; Dr J Martin; Professor I C S Normand; Mr J Peto; Dr M Radford; $\mathrm{Mr}$ P G Smith; Dr J Stuart; Dr E N Thompson; Dr M L N Willoughby.
}

relapses occurred less in older patients and those with higher leucocyte counts initially than in those who appeared to have the best prognosis-namely, those with typical low-count childhood ALL. No patient given prophylactic irradiation to cranium and spine combined with intrathecal methotrexate suffered meningeal relapses, whereas among those not given such prophylaxis the lack of benefit from continuing treatment was mainly attributable to meningeal relapses.

\section{Introduction}

There is as yet no consensus on the optimum duration of treatment for acute lymphoblastic leukaemia (ALL), though three years has been most commonly used. ${ }^{12}$ A Medical Research Council trial (UKALL I) was designed to answer the question and we report here the results.

\section{Plan of trial}

Patients entered the trial from August 1970 to 31 December 1971. The trial protocol and preliminary data were reported previously, ${ }^{3}$ 